\title{
Rebuke to the enthusiastic culture of medical screening
}

\author{
Over-Diagnosed: Making People Sick in \\ the Pursuit of Health \\ H. Gilbert Welch, Lisa M. Schwartz and \\ Steven Woloshin \\ Beacon Press; 2011.
}

I $\mathrm{n}$ the interest of full disclosure, I was aware this book was coming long before it was published, so I already had high expectations when it finally arrived on my desk. I had interviewed the author, Dr. H. Gilbert Welch for a radio documentary on CBC's Ideas in 2008 (for a segment called "You are 'Pre-Diseased'") delving into the way the practice of medicine seemed to be so skillfully - and sometimes so unnecessarily - turning people into patients. Admittedly smitten by the intriguing title to his 2004 book, Should I be Tested for Cancer? Maybe Not and Here's Why, I knew Welch would have some provocative things to say.

That book shone a strong light in the dark corners of cancer screening, lighting up a world most of us - patients, physicians and health policy-makers take for granted. He made the argument that society's obsessive hunt to screen for and find cancers in well people could be putting entire populations at risk, without the chance of reward. I wondered how he could better himself

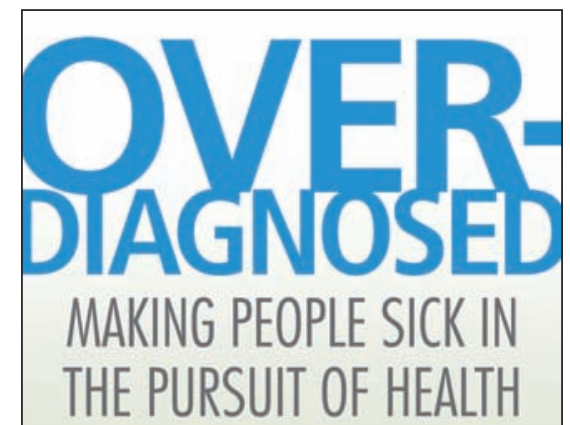

DR. H. GILBERT WELCH,

DR. LISA M. SCHWARTZ, AND DR. STEVEN WOLOSHIN

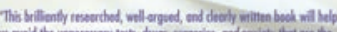

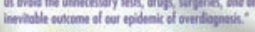

- SIDNEY WOUFE, MD, whthor of

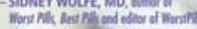

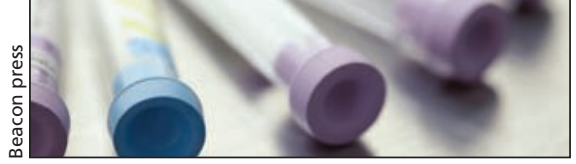

Bozeman, Montana. Over-Diagnosed is the book that emerged from that sabbatical, and it makes a fine addition to our understanding of the problems of unnecessary diagnoses and treatments. In it he deconstructs the "test early, test often" paradigm of medicine, which holds as a near sacred truth that early aggressive screening and treatment will always benefit the patient.

Welch knows how to wield an analogy, and he hits the mark when he likens our overdiagnosing medical cul-

\section{When you start treating people who don't stand to benefit, they can only be harmed.}

at dissecting this critical part of medical orthodoxy on population screening in a new book. Yet he has.

Normally practising medicine with the Veterans Affairs in White River Junction, Vermont, along with his colleagues and coauthors Lisa M. Schwartz and Steven Woloshin, Welch was taking a sabbatical leave when I tracked him down at Montana State University in ture to the many "check engine" lights that litter the dashboards of our modern automobiles. His ' 65 Ford Fairlane wagon had only a few sensors, measuring oil pressure and engine temperature, and when the wagon's dashboard lights were flashing red, it was worth a stop to investigate. By contrast his '99 Volvo is stuffed with electronic sensors and warning lights in a tangle so com- plicated that their behaviours need to be guided by computers. When check engine lights flash potential trouble, the vehicle's operator has to determine if it is a false alarm, or a signal of something that could go horribly wrong and needs instant investigation. Sometimes we are glad the light is telling us we are overheating, but more often than not the problem is in the sensor, not in the thing it was supposed to sense. Such alarm systems create safer-running automobiles but, along the way, also cause much worrying, and sometimes expensive investigations that turn out to be for naught.

From the problems we have in seeking the results of high-tech scans for gallstones, damaged knee cartilage or bulging discs, to the many issues that arise as we seek cancers in breasts, lungs and prostates, Welch delivers a measured and logical rebuke to the enthusiastic culture of medical screening. The result of all the screening, scanning and diagnosing is the discovery of a lot more disease, but in its wake it leaves a patient population obsessed by numbers, subjected to biopsies and investigations on things that would never have hurt them and often no better off in the long run. The biggest problem the book explains is that when you start treating people who don't stand to benefit, they can only be harmed, suffering the ill effects of surgery, chemotherapy and radiation.

Readers will find much delight in Over-Diagnosed and may even have their minds changed in the course of reading this book. Welch reiterates the point made in his previous book that cancer likely isn't what you think it is and that most of us are harbouring cancerous cells that will never go on to hurt us. His strongest critique perhaps comes when he talks about prostate-specific antigen testing, making the bold statement that as 
many as two million American men may have been treated for prostate cancer that never would have hurt them. He wields the term "incidentaloma," apparently coined by radiologists to refer to small nodules detected on a scan found in the liver, the lung or the kidney, which could be cancer but almost never are.

Health economist J.D. Kleinke wrote that "the blessing and the curse of modern medicine ... is its ability to stimulate its own demand." ${ }^{\prime}$ No part of medicine better exemplifies this than medical screening, which creates demand for more diagnoses and more medical interventions. Over-Diagnosed urges us to look for sound medical evidence of benefit and harm - before submitting to measures that only deliver more diagnoses.

The threshold of what is considered "normal" has changed in the last 20 years. Over-Diagnosed reminds us that if we construct health as the absence of abnormality, we'd find that few of us are healthy. When we look harder and harder for anomalies, testing well people who have no symptoms, we're taking the first dangerous step for overdiagnosis to occur. Until medicine takes a more critical view of screening, we will still continue to be dazzled by all the check engine sensors lighting up our dashboards.

\section{Alan Cassels MPA}

Drug policy researcher

University of Victoria

Victoria, BC

\section{Reference}

1. Kleinke JD. A normal pregnancy is a retrospective diagnosis. The Health Care Blog 29 March 2011. Available: http://thehealthcareblog.com/blog /2011/03/29/pregnancy/ (accessed 2011 Oct. 27).

CMAJ 2012. DOI:10.1503/cmaj.111685 